\title{
ANTI-PERIODIC SOLUTIONS OF ABEL DIFFERENTIAL EQUATIONS WITH STATE DEPENDENT DISCONTINUITIES
}

\author{
J.-M. Belley And A. Gueye
}

Abstract. Given $T>0$, the Abel-like equation $\theta^{\prime}=f_{0}+\sum_{j \in \mathbb{N}} f_{j} \theta^{j}$ is generalized to the case where $\theta$ and $\theta^{\prime}$ are real functions on $[0, T]$ subject to given state dependent discontinuities. Each $f_{j}$ is a real function of bounded variation for which $f_{j}(0)=(-1)^{j+1} f_{j}(T)$. Under appropriate conditions, this equation is shown to admit a solution of bounded variation on $[0, T]$ which is $T$-anti-periodic in the sense that $\theta(0)=-\theta(T)$. The contraction principle yields a bound for the rate of uniform convergence to the solution of a sequence of iterates.

Mathematics subject classification (2010): 34A37, 34B15, 34B37, 34C25.

Keywords and phrases: Abel equation, anti-periodic solutions, state dependent jumps, Hilbert's $16^{\text {th }}$ problem.

\section{REFERENCES}

[1] A. R. Aftabizadeh, S. Aizicovici and N. H. Pavel, On a class of second-order anti-periodic boundary value problems, J. Math. Anal. Appl. 171 (1992), 301-320.

[2] B. AhmAD AND J. J. NiETo, Existence and approximation of solutions for a class of nonlinear impulsive functional differential equations with anti-periodic boundary conditions, Nonlinear Analysis: Theory, Methods \& Applications 69 (2008), 3291-3298.

[3] C. D. Aliprantis and O. Burkinshaw, Principles of real analysis. Second edition, Academic Press, Inc., Boston, MA, 1990.

[4] N. M. H. Alkoumi AND P. J. TORRES, Estimates on the number of limit cycles of a generalized Abel equation, Discrete contin. Dyn. Syst. 31 (2011), 25-34.

[5] N. M. H. AlKoumi AND P. J. TORRes, On the number of limit cycles of a generalized Abel equation, Czechoslovak Math. J. 61(136) (2011), 73-83.

[6] A. Álvarez, J. L. Bravo, And M. Fernández, Limit cycles of Abel equations of the first kind, J. Math. Anal. Appl. 423 (2015), 734-745.

[7] A. Álvarez, J. L. Bravo, And M. Fernández, Existence of non-trivial limit cycles in Abel equations with symmetries, Nonlinear Anal. 84 (2013), 18-28.

[8] A. Álvarez, J. L. Bravo, And M. FernándeZ, Abel-like differential equations with unique limit cycle, Nonlinear Anal. 74 (2011), 3694-3702.

[9] A. Álvarez, J. L. Bravo, And M. Fernández, The number of limit cycles for generalized Abel equations with periodic coefficients of definite sign, J. Math. Anal. Appl. 360 (2009), 168-189.

[10] A. Álvarez, J. L. Bravo, And M. Fernández, Existence of non-trivial limit cycles in Abel equations with symmetries, Commun. Pure Appl. Anal. 8 (2009), 1493-1501.

[11] D. Batenkov And G. Binyamini, Uniform upper bounds for the cyclicity of the zero solution of the Abel differential equation, J. Differential Equations 259 (2015), 5769-5781.

[12] J. L. BRAVo AND M. FernándeZ, Stability of singular limit cycles for Abel equations, Discrete Contin. Dyn. Syst. 35 (2015), 1873-1890.

[13] T. CHEN AND W. LIU, Anti-periodic solutions for higher-order Liénard type differential equation with p-Laplacian operator, Bull. Korean Math. Soc. 49 (2012), 455-463.

[14] Y. Chen, J. J. Nieto And D. O'Regan, Anti-periodic solutions for fully nonlinear first order differential equations, Mathematics and Computer Modelling 46 (2007), 1183-1190. 
[15] Y. Chen, J. J. NiETO AND D. O'REGAN, Anti-periodic solutions for evolution equations associated with maximal monotone mappings, Applied Mathematics Letters 24 (2011), 302-307.

[16] H. F. DAVIS, Fourier series and orthogonal functions, Allyn and Bacon, Inc., Boston, MA, 1963.

[17] W. Ding, Y. XING AND M. HAN, Anti-periodic boundary value problems for first order impulsive functional differential equations, Applied mathematics and Computation 186 (2007), 45-53.

[18] D. Franco, J. J. Nieto AND D. O'REgAn, Anti-periodic boundary value problem for nonlinear first order ordinary differential equations, Mathematical Inequalities \& Applications 6 (2003), 477485.

[19] A. Gasull And Y. ZhaO, On a family of polynomial differential equations having at most three limit cycles, Huston J. Math. 39 (2013), 191-203.

[20] T. JANKOWSKI, Ordinary differential equations with nonlinear boundary conditions of antiperiodic type, Computers \& Mathematics with Applications 6 (2004), 1419-1428.

[21] G. Jaume, G. Maite and L. Jaume, Universal centres and composition conditions, Proc. Lond. Math. Soc. 106 (2013), 481-507.

[22] Y. KATZNELSON, An introduction to harmonic analysis, John Wiley \& Sons, Inc., New York, 1968.

[23] Y. Li AND L. HUANG, Anti-periodic solutions for a class of Liénard-type systems with continuously distributed delays, Nonlinear Analysis: Real World Applications 10 (2009), 2127-2132.

[24] L. LiU AND Y. LI, Existence and uniqueness of anti-periodic solutions for a class of nonlinear n-th order functional differential equations, Opuscula Mathematica 31 (2011), 61-74.

[25] M. NaKao AND H. OKochI, Anti-periodic solution for $u_{x x}-\left(\sigma\left(u_{x}\right)\right)_{x}-u_{x x t}=f(x, t)$, J. Math. Anal. Appl. 197 (1996), 796-809.

[26] Н. Окосні, On the existence of anti-periodic solutions to a nonlinear evolution equation associated with odd subdifferential operators, J. Funct. Anal. 91 (1990), 246-258.

[27] H. ОкоснI, On the existence of anti-periodic solutions to nonlinear parabolic equations in non cylindrical domains, Nonlinear Anal. 14 (1990), 771-783.

[28] H. Окосні, On the existence of periodic solutions to nonlinear abstract parabolic equations, J. Math. Soc. Japan 40 (1988), 541-553.

[29] C. OU, Antiperiodic solutions for high-order Hopfield neural networks, Computers \& Mathematics with Applications 56 (2008), 1838-1844.

[30] F. PAHOVICH, Weak and strong composition conditions for the Abel differential equation, Bull. Sci. math. 138 (2014), 993-998.

[31] H. L. Royden, Real Analysis. Third edition, Macmillan Publishing Company, New York, 1988.

[32] W. Rudin, Real and Complex Analysis. Third edition, McGraw-Hill Book Company, New York, 1987.

[33] K. WANG, A new existence result for nonlinear first-order anti-periodic boundary value problems, Applied Mathematics Letters 21 (2008), 1159-1154.

[34] R. Wu, An anti-periodic LaSalle oscillatory theorem, Applied Mathematics Letters 21 (2008), 928 933.

[35] Y. YIN, Remarks on first order differential equations with anti-periodic boundary conditions, Nonlinear Times and Digest 2 (1995), 83-94.

[36] Y. YIN, Monotone iterative technique and quasilinearization for some anti-periodic problems, Nonlinear World 3 (1996), 253-266.

[37] A. H. Zemanian, Distribution Theory and Transform Analysis, Dover Publications, Inc., Minneola, N.Y., 1987. 